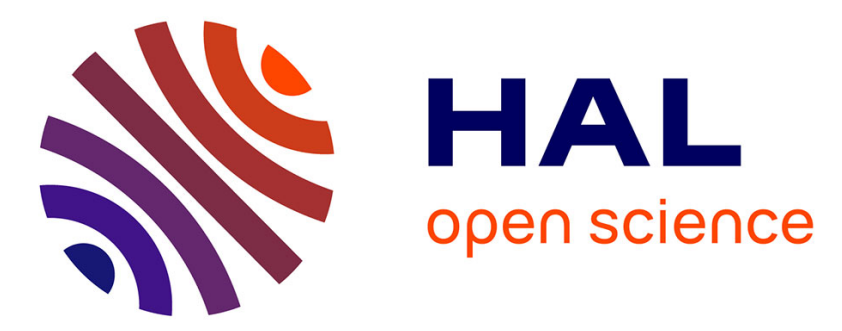

\title{
Human skin stem cells and the ageing process
}

Christos C. Zouboulis, James Adjaye, Hirohiko Akamatsu, Gerd Moe-Behrens, Catherin Niemann

\section{To cite this version:}

Christos C. Zouboulis, James Adjaye, Hirohiko Akamatsu, Gerd Moe-Behrens, Catherin Niemann. Human skin stem cells and the ageing process. Experimental Gerontology, 2008, 43 (11), pp.986. 10.1016/j.exger.2008.09.001 . hal-00499064

\section{HAL Id: hal-00499064 https://hal.science/hal-00499064}

Submitted on 9 Jul 2010

HAL is a multi-disciplinary open access archive for the deposit and dissemination of scientific research documents, whether they are published or not. The documents may come from teaching and research institutions in France or abroad, or from public or private research centers.
L'archive ouverte pluridisciplinaire HAL, est destinée au dépôt et à la diffusion de documents scientifiques de niveau recherche, publiés ou non, émanant des établissements d'enseignement et de recherche français ou étrangers, des laboratoires publics ou privés. 


\section{Accepted Manuscript}

Human skin stem cells and the ageing process

Christos C. Zouboulis, James Adjaye, Hirohiko Akamatsu, Gerd Moe-Behrens, Catherin Niemann

PII:

S0531-5565(08)00292-1

DOI:

10.1016/j.exger.2008.09.001

Reference:

EXG 8542

To appear in:

Experimental Gerontology

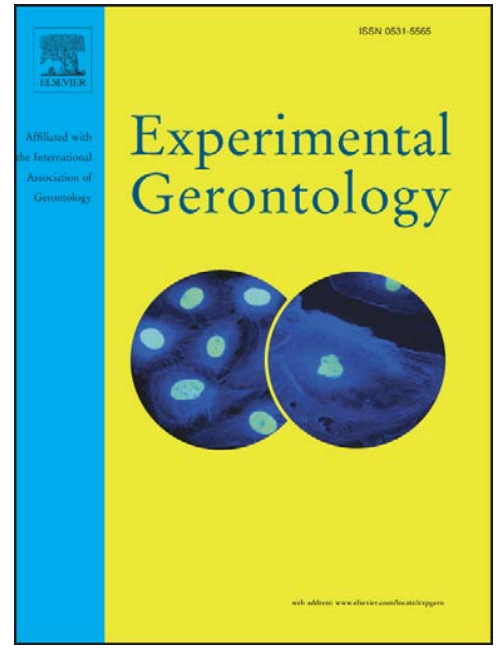

Received Date: $\quad 12$ May 2008

Revised Date: $\quad 31$ August 2008

Accepted Date: $\quad 1$ September 2008

Please cite this article as: Zouboulis, C.C., Adjaye, J., Akamatsu, H., Moe-Behrens, G., Niemann, C., Human skin stem cells and the ageing process, Experimental Gerontology (2008), doi: 10.1016/j.exger.2008.09.001

This is a PDF file of an unedited manuscript that has been accepted for publication. As a service to our customers we are providing this early version of the manuscript. The manuscript will undergo copyediting, typesetting, and review of the resulting proof before it is published in its final form. Please note that during the production process errors may be discovered which could affect the content, and all legal disclaimers that apply to the journal pertain. 


\section{Human skin stem cells and the ageing process}

Christos C. Zouboulis ${ }^{\mathrm{a}, \mathrm{b}}$, James Adjaye ${ }^{\mathrm{c}}$, Hirohiko Akamatsu ${ }^{\mathrm{d}}$, Gerd Moe-Behrens ${ }^{\mathrm{c}}$ and Catherin Niemann ${ }^{\mathrm{e}}$

${ }^{\mathrm{a}}$ Departments of Dermatology, Venereology, Allergology and Immunology, Dessau Medical Center, Auenweg 38, 06847 Dessau, Germany

${ }^{\mathrm{b}}$ Laboratory for Biogerontology, Dermato-Pharmacology and Dermato-Endocrinology, Institute of Clinical Pharmacology and Toxicology, Charité Universitaetsmedizin Berlin, Campus Benjamin Franklin, Garystrasse 5, 14195 Berlin, Germany

${ }^{\mathrm{c}}$ Department of Vertebrate Genomics, Max Planck Institute for Molecular Genetics, Ihnestrasse 73, 14195 Berlin, Germany

${ }^{\mathrm{d}}$ Department of Dermatology, Fujita Health University School of Medicine, 1-98

Kutsukake-cho, Toyoake, Aichi 470-1192, Japan

${ }^{\mathrm{e}}$ Department of Pathology, Center for Molecular Medicine Cologne (CMMC), University of Cologne, Joseph-Stelzmann-Strasse 9, 50931 Cologne, Germany

Running Title: Skin stem cells and ageing

Key words: Stem cells, skin, skin physiology, ageing

Correspondence:

Prof. Dr. Christos C. Zouboulis, Departments of Dermatology, Venereology, Allergology and Immunology, Dessau Medical Center, Auenweg 38, 06847 Dessau, Germany

Tel.: +49-340-5014000 / Fax: +49-340-5014025, E-mail: christos.zouboulis@klinikumdessau.de 


\begin{abstract}
In healthy individuals, skin integrity is maintained by epidermal stem cells which selfrenew and generate daughter cells that undergo terminal differentiation. Despite accumulation of senescence markers in aged skin, epidermal stem cells are maintained at normal levels throughout life. Therefore, skin ageing is induced by impaired stem cell mobilisation or reduced number of stem cells able to respond to proliferative signals. In the skin, existence of several distinct stem cell populations has been reported. Genetic labelling studies detected multipotent stem cells of the hair follicle bulge to support regeneration of hair follicles but not been responsible for maintaining interfollicular epidermis, which exhibits a distinct stem cell population. Hair follicle epithelial stem cells have at least a dual function: hair follicle remodelling in daily life and epidermal regeneration whenever skin integrity is severely compromised, e.g. after burns. Bulge cells, the first adult stem cells of the hair follicle been identified, are capable of forming hair follicles, interfollicular epidermis and sebaceous glands. In addition - at least in murine hair follicles -, they can also give rise to non-epithelial cells, indicating a lineageindependent pluripotent character. Multipotent cells (skin-derived precursors cells) are present in human dermis, dermal stem cells represent $0.3 \%$ among human dermal foreskin fibroblasts. A resident pool of progenitor cells exists within the sebaceous gland, which is able to differentiate into both sebocytes and interfollicular epidermis. The selfrenewal and multi-lineage differentiation of skin stem cells make these cells attractive for ageing process studies but also for regenerative medicine, tissue repair, gene therapy and cell-based therapy with autologous adult stem cells not only in dermatology. In addition, they provide in vitro models to study epidermal lineage selection and its role in the ageing process.
\end{abstract}




\section{The concept of stem cells and their role in ageing}

\subsection{The concept of stem cells}

The earliest stages of human cellular differentiation occur during the transition from the morula to blastocyst stage of preimplantation development, and give rise to divergent lineages. These are: 1) the trophectoderm (TE), which gives rise to the cytotrophoblast and syncytiotrophoblast of the placenta and the primitive endoderm, and 2) the inner cell mass, which generates the embryo proper and extraembryonic tissues (Adjaye et al., 2005; Gardner et al., 1988). The inner cell mass is the source of embryonic stem (ES) cells, which have the ability to self-renew, thus they are able to go through numerous cycles of cell division while maintaining the undifferentiated state. Moreover, ES cells are pluripotent, which implies that they are capable of differentiating into cells representing the three primary germ layers - endoderm, ectoderm and mesoderm (Thomson et al., 1998).

Unlike ES cells, which are pluripotent and can generate all cell types, adult stem cells are thought to be more fate restricted, but still possess other characteristics of ES cells self-renewal, long life, high proliferative potential and can give rise to several other cell types (multipotency) (reviewed in Sharpless and DePinho, 2007). Replication of stem cells can occur either symmetrically when a stem cell division gives rise to two identical stem cells or asymmetrically when a stem cell produces an identical and a more differentiated daughter cell (Fig. 1). ES cells divide symmetrical, whereas asymmetrical cell division can be found in adult stem cells.

These rare and specialised adult stem cells are required for tissue replacement throughout the lifespan of an organism. Stem cells in several tissues are largely retained in a quiescent state but can be coaxed back into the cell cycle in response to extracellular cues. Once stimulated to divide, stem cells yield undifferentiated progenitors which are relatively undifferentiated cell types that are derived from asymmetric stem cell division and lack the capacity to self-renew (Fig. 2). The progenitors in turn produce differentiated effector cells through subsequent rounds of proliferation (Fig. 2). Resident self-renewing cells are thought to have a significant role in the homeostasic maintenance 
of many organs and tissues. One example is the epidermis, which has a 'high cellular turnover' and high regenerative potential (Rando, 2006). The result of uncontrolled selfrenewal is malignant transformation. Unrepaired gene lesions in stem cells are passed on to their self-renewing daughters and accumulate with ageing. When mutations occur despite of mechanisms aimed to maintaining genomic integrity, potent tumour suppressing mechanisms such as senescence and apoptosis exist to sense damaged stemcell genomes with malignant potential and limit replicative expansion. Senescence and apoptosis, which rely on telomere shortening and/or activation of growth inhibitory molecules such as cyclin-dependent kinase inhibitor p16INK4a and the tumour suppressor p53 appear to promote ageing.

\section{2. Niche}

Stem cell niches are composed of microenvironmental cells that nurture stem cells and enable them to maintain tissue homeostasis (Fig. 2) (Moore and Lemischka, 2006). An appropriate spatiotemporal dialog occurs between stem and niche cells in order to fulfil lifelong demands for differentiated cells. Niche cells provide a sheltering environment that sequesters stem cells from differentiation stimuli, apoptotic stimuli, and other stimuli that would challenge stem cell reserves. The niche also safeguards against excessive stem cell production that could lead to cancer. Moreover, maintaining a balance of stem cell quiescence and activity is a hallmark of a functional niche.

\section{3. Intrinsic and extrinsic signals}

The self-renewing stem cell might grow old as a result of inherent (intrinsic) events, such as DNA damage, as well as external (extrinsic) forces, such as changes in their supporting niches. A constellation of intrinsic and extrinsic signals regulates the balance of self-renewal and differentiation in all stem cells (Moore and Lemischka, 2006).

\subsection{The role of the stem cell in ageing}


The decline of tissue regenerative potential is a hallmark of ageing and may be due to age related changes in tissue-specific stem cells (Conboy et al., 2005). Stem cell numbers and self-renewal capabilities do not necessarily decline with age, but rather its function - ie the ability to produce progenitors and differentiated effector cells declines with age (Sharpless and DePinho, 2007) (Fig. 2).

\subsection{Stem cells might have a finite number of replications per life}

As we grow old, our stem cells might lose replicative capacity, and this in turn causes some aspects of ageing. Deficiencies of DNA repair have been suggested as one underlying mechanism (Krishnamurthy and Sharpless, 2007). Deletion of the developmental essential gene ataxia-telangiectasia and Rad3-related (ATR) in adult mice resulted in age-related phenotypes and stem cell loss (Ruzankina et al., 2007). ATR is a PI3K-like kinase that activates multiple downstream signalling networks in response to DNA damage. Eliminating ATR in adult mice, by an inducible conditional knockout, leads to defects in tissue homeostasis and the rapid appearance of progeroid phenotypes, including hair greying, alopecia, kyphosis, osteoporosis, thymic involution, fibrosis. Thymic involution, alopecia, and hair greying in ATR mosaic knockout mice were associated with reductions in tissue-specific stem (bulge) and progenitor (thymic) cells and exhaustion of tissue renewal and homeostatic capacity. These phenotypes occur in tissues in which virtually all the cells harbour the intact ATR allele. This finding indicates that the accelerated ageing occurs in ATR-competent tissues and therefore is the result of forced regeneration rather than ATR deficiency. This study suggests that reduced regenerative capacity in adults via deletion of a developmentally essential DNA damage response gene is sufficient to cause the premature appearance of age-related phenotypes and that replication itself has effects on the self-renewing compartments. Obligate tissue regeneration leads to stem cell exhaustion in a few compartments, contributing to the ageing phenotype observed. Cellular depletion can act in an extrinsic manner to induce ageing. That is, stem cell exhaustion can occur as a result of proliferative stress forced through normal homeostatic mechanisms. A barrier, which is to the present unkown in their molecular nature, may limit how many times a stem cell can 
divide. However, this study does not tell us in which ATR-competent cells the ageing actually occurs. This study leaves open questions, such as, is the ATR excision and subsequent regeneration detrimental to the niche rather than the self-renewing cells?

\subsection{Intrinsic changes in blood stem cells have a role in ageing}

In most mammalian tissues the inability to purify the resident stem cell to homogeneity, as well the lack of adequate models to test the function of these cells, has made it difficult to determine if a decline in stem cell function is a cause of the degeneration of the regenerative capacities that is seen in many organs with ageing. However, in the hematopoietic system, it is possible to purify hematopoietic stem cells to near homogeneity and assay their function using validated assays (Sharpless and DePinho, 2007). Thus the age dependent change can be studied in a single cell type. To understand the mechanisms underlying hematopoietic ageing, highly purified long-term hematopoietic stem cells (LT-HSCs) from young and old mice have been compared (Rossi et al., 2005). Furthermore, a genome-wide expression profile of ageing stem cells has been generated. It was found that LT-HSC ageing was accompanied by cell autonomous changes including increased stem cell self-renewal, differential capacity to generate committed myeloid and lymphoid progenitors, and diminished lymphoid potential. Expression profiling revealed that 907 genes (out of $\sim 34000$ genes screened) were age regulated to a high degree of statistical confidence (http://genomewww5.stanford.edu). Analysis of the microarray data revealed significant statistical overrepresentation of several gene ontology categories in the age-regulated genes. Of these, genes involved in signal transduction activity and receptor activity were found to be

highly over-represented in ageing LT-HCSs. The majority of the genes within these categories fell into several sub-categories including genes involved in transmembrane receptor activity, $\mathrm{G}$ protein-coupled receptor binding, transmembrane receptor protein tyrosine kinase activity, and protein tyrosine phosphatase activity. Thus the differential expression of genes involved in cell signalling is a central underlying molecular feature of LT-HSC ageing. It is noteworthy that several of the functional categories that have previously been reported to accompany ageing of other tissues such as DNA repair, stress 
response and inflammation were not found to be differentially regulated in ageing LTHSCs. Moreover, LT-HSC ageing was accompanied by the systemic down-regulation of genes mediating lymphoid specification and function and up-regulation of genes involved in specifying myeloid fate and function. In addition, LT-HSCs from old mice expressed elevated levels of many genes involved in leukemic transformation. Taken together, these data suggest that many of the features that underlie ageing of the murine hematopoietic system result directly from intrinsic changes that occur at the level of LT-HSCs. Based on observations in haematopoietic cells, it has been suggested that stem cells directly regulate tissue ageing (Giangreco et al., 2008).

\subsection{Local environment rather than stem cell intrinsic factors might influence skin ageing}

In healthy individuals, skin integrity is maintained by epidermal stem cells which selfrenew and generate daughter cells that undergo terminal differentiation (Giangreco et al., 2008). Despite clear evidence that aged skin accumulates senescence markers such as p16/Ink4a/Arf, it remains controversial whether epidermal stem cells intrinsically age (Ressler et al., 2006). Genetically engineered telomerase deficient mice have been generated, these exhibit characteristics of premature skin ageing (Flores et al., 2005). However, it remains unclear whether these changes are caused by stem cell intrinsic telomerase deficiencies. In vitro culture studies suggest that aged mouse epidermal keratinocytes function equivalently to those isolated from young animals (Stern et al., 2007). Thus, murine skin stem cells might be resistant to intrinsic ageing. In contrast, skin cells isolated from elderly humans and cultured under similar conditions contained fewer stem-like cells (Barrandon et al., 1987). Abundance, organization and proliferation of young and aged murine skin stem cells (bulge cells) have been compared (Giangreco et al., 2008). Despite age associated differences in epidermal proliferation, dermal thickness, follicle patterning, and immune cell abundance, epidermal stem cells are maintained at normal levels throughout life. These findings, coupled with the observed changes in dermal gene expression, would suggest that epidermal stem cells themselves are resistant to intrinsic ageing and that local environmental or systemic factors modulate 
skin ageing. These data suggest that extrinsic signals, dermis-derived factors e.g. from cells in the stem cell niche might regulate skin ageing.

\subsection{The Stem cell niche plays an important role in determining stem cell function with} age

In fact, the stem cell niche has been demonstrated in other systems to play an important role in determining stem cell function with age (Conboy et al., 2005). A decline in skeletal muscle stem cell (satellite cell) activity due to loss of Notch signalling results in impaired regeneration of aged muscle. The decline in hepatic progenitor cell proliferation due to the formation of a complex involving cEBP- $\alpha$ and the chromatin remodelling factor brahma (Brm) inhibits the regenerative capacity of aged liver. Exposure of satellite cells from old mice to young serum enhanced the expression of the Notch ligand (Delta), increased Notch activation, and enhanced proliferation in vitro. Moreover, similar exposure to young serum increased aged hepatocyte proliferation and restored the cEBP$\alpha$ complex to levels seen in young animals. These data suggest that rejuvenation of aged progenitor cells can be achieved by exposure to a young systemic environment. Thus the age related decline of progenitor cell activity can be modulated by systemic factors that change with age.

\section{Epidermal stem cells}

The interfollicular epidermis of human skin is a multilayered stratified squamous epithelium which is constantly renewed throughout life. The mammalian interfollicular epidermis provides the first line of defence against environmental damaging agents and therefore constitutes an important barrier to prevent harmful elements from disturbing tissue homeostasis and to keep essential fluids within the body. The interfollicular epidermis maintains homeostasis by proliferation of keratinocytes in the basal layer attached to the underlying basement membrane. As basal cells detach from the basement membrane they withdraw from the cell cycle and initiate a program of terminal differentiation to gradually move upward to the skin surface. Upon initiation of the 
differentiation program keratinocytes progress through different stages to constitute three distinct layers of the epidermis: spinous layer followed by the granular layer and finally keratinocytes lose the nuclei to become flattened cornified cells comprising the stratum corneum (Fig. 3). Cornified cells are continuously shed from the surface of the skin and therefore new differentiated cells must be generated throughout life.

Replenishment of the differentiation compartment depends on proliferation of a subpopulation of cells in the basal layer, known as stem cells. The model that is most widely accepted is that upon division, a stem cell can produce a stem cell daughter and a committed progenitor cell, called transit amplifying cell (TA cell). The TA stem cell daughter that is destined to undergo terminal differentiation can first divide a small number of times (estimated 5 times) (Fuchs, 2008). There is good evidence for the existence of a distinct stem cell population within the interfollicular epidermis. Genetic labelling studies revealed that whereas multipotent stem cells of the hair follicle bulge support regeneration of hair follicles, they are not responsible for maintaining interfollicular epidermis (Levy et al., 2005). In addition, depletion of bulge cells in a transgenic mouse model leads to loss of hair follicle structures but not of the interfollicular epidermis (Ito et al., 2004). Stimulation of epidermal stem cells with appropriate mesenchymal signals induces differentiation into hair keratinocytes or sebocytes demonstrating that epidermal stem cells are capable to differentiate along multiple lineages of mouse skin (Niemann and Watt, 2002). Given the increasing excitement evoked by epidermal stem cells due to their potential for therapeutic application and as reservoir for adult stem cells in other clinical settings it seems important to understand where stem cells are localised within the basal layer of the epidermis and to identify reliable marker molecules applicable to isolate epidermal stem cells.

Studies on mouse and human epidermis performed many years ago revealed that long-lived stem cells residing within the basal layer generate TA and differentiated progeny thereby forming a column of clonal keratinocytes extending from the basal stem cell to the surface of the tissue known as epidermal proliferative units (EPUs). This EPU model has led to the hypothesis that a single stem cell surrounded by a cluster of TA cells in the basal layer together with the overlying suprabasal and differentiated cell layers 
form a distinct spatial unit in human and mouse tissue. This EPU model implies that only a small number of stem cells exist within the basal layer with each stem cell being enclosed by a microenvironment providing all required signals for stem cell activation and renewal (Potten, 1974). The EPU model has been challenged recently by lineage tracing experiments performed on mouse tail skin demonstrating that a committed progenitor cell population is able to maintain normal adult epidermis (Clayton et al., 2007). In the future it will be interesting to find out if a hierarchy of different progenitor population with distinct properties exist within human interfollicular epidermis ranging from primitive quiescent stem cells to more committed and frequently activated precursor cells.

In vivo, spatial differences in expression levels of stem cell marker molecules indicate the existence of distinct cell populations supporting the EPU model. For instance, human epidermal cells producing high levels of $\beta 1$-integrin give rise to large colonies (holoclones) in an in vitro colony-forming efficiency assay, whereas cells expressing low levels of $\beta 1$-integrin produce smaller meroclones (Jones and Watt, 1993). The clonogenicity assay is widely used as clonal assay of proliferation of human keratinocytes as indication of extensive self-renewal and generation of differentiated progeny by the epidermal stem cell compartment (Barrandon and Green, 1987). A range of other marker molecules have been described for enrichment of human epidermal stem cells including high $\alpha 6$ integrin and low CD71 expression, high expression of the notch signalling ligand Delta1 and high expression of CD200 (Li et al., 1998; Lowell et al., 2000; Ohyama et al., 2006). Furthermore, melanoma-associated chondroitin sulphate proteoglycan and Lrig1 (leucine-rich repeats and immunoglobulin-like domains 1) have been shown to be associated with basal keratinocytes that were not actively cycling (Legg et al., 2003; Jensen and Watt, 2006). Indeed, Lrig1 when over-expressed can decrease proliferation probably by reducing epidermal growth factor (EGF) receptor levels and has been proposed to maintain epidermal stem cells in quiescent non-dividing state. However, there is still not much known about the essential signalling factors regulating stem cell maintenance and function in human interfollicular epidermis.

With ageing, the epidermis becomes more fragile and susceptible to trauma (Legg et al., 2003; Jensen and Watt, 2006). Are epidermal stem cells affected by ageing? Impaired 
wound healing rate in aged skin suggest either impaired stem cell mobilisation or reduced number of stem cells able to respond to proliferative signals. In support for this hypothesis it has been shown several years ago that keratinocytes isolated from older human donors give rise to a lower proportion of holoclones in the clonogenicity assay when compared to epidermal cells originating from younger donors (Barrandon and Greene, 1987). In addition, it has been presented that the number of cells positive for $\mathrm{p} 16^{\mathrm{INK} 4 \mathrm{~A}}$, a molecule playing an essential role in mediating G1 arrest, is significantly increased in human epidermal cells from elderly individuals. However, it is not clear if this difference is also seen in the epidermal stem cell compartment (Ressler et al., 2006). Epidermal stem cells display longer telomeres when compared to TA cells and this seems to be a more general feature for stem cells of different tissues and interestingly, it has been found that telomeres shorten with age in stem cell compartments (Flores et al., 2008). Recent data indicate that stem cells of the mouse skin are retained throughout skin ageing and are resistant to cellular ageing implying an important function for local environmental factors responsible for age associated skin abnormalities. One potential relevant signalling pathway regulating stem cell niche in the ageing process is activated by members of the insulin-like growth factor family but further detailed investigations are required (Stern and Bickenbach, 2007; Giangreco et al., 2008). Until now, it is not clear when exactly the epidermal stem cell niche is established during development and how it is preserved during ageing. Generally, the potential role of soluble factors, the dermal compartment and components of the extracellular matrix in mobilisation of epidermal stem cells, establishing a stem cell niche and maintaining it in the process of ageing are elusive up to date and will be one of the challenging questions for future research.

\section{Stem cells of the hair follicle}

\subsection{Follicular cycling}

The portrait of the adult hair follicle as a miniorgan that consists of an upper, permanent portion and a lower, constantly remodelled, cycling portion, the anagen hair bulb, is nowadays consider as over-simplification (Tiede et al., 2007) (Fig. 4). There is essentially 
no tissue compartment of the pilosebaceous unit that escapes at least some degree of remodelling during the massive organ transformations that characterize the hair follicle cycle with its periodic self-renewal at predetermined intervals (Paus and Foitzik, 2004). The regeneration of the anagen hair bulb is the most obvious of these cyclic remodelling events. These events require the presence of fully functional epithelial stem cell (eSC) populations, which are capable of constructing all epithelial differentiation strata. Following a period of apoptosis-driven epithelial regression (catagen) and a subsequent period of relative quiescence (telogen), a new hair matrix, inner and outer root sheath companion layer, and hair shaft are generated from these eSC. This occurs during each new anagen phase under the control of an inductive, specialized mesenchyme (Cotsarelis et al., 1990).

\subsection{Epithelial stem cells of the hair follicle}

While under physiological conditions, hair follicle eSC appear to be programmed to maintain and regenerate only the epithelium of the cycling hair follicle, under conditions of trauma, wounding, and upon various inflammatory stimuli, they can also completely regenerate a lost epidermis, e.g. after burns (Ito et al., 2005). Thus, hair follicle eSC have at least a dual function: hair follicle remodelling in daily life and epidermal regeneration whenever skin integrity is severely compromised.

Stem cells of the basal layer of the interfollicular epidermis do not regenerate lost hair follicles (e.g. during scarring alopecia) (Tiede et al., 2007). Therefore, hair follicle eSC are programmed during hair follicle development to undergo exclusively hair follicletype differentiation, but they can be re-programmed to expand into essentially all pathways of epithelial differentiation (Fuchs and Horsley, 2008). Hair shaft production and hair follicle cycling depend on stringent interactions with an underlying, specialized mesenchyme, which also undergoes substantial cyclic remodelling events.

\subsection{The bulge region}


In rodents, the outer root sheath between the non-cycling and cycling segments contains a discrete projection, which has been identified to contain slow cycling label-retaining cells. In mice, this bulge region is situated between the attachment site for the arrector pili muscle and marks the bottom of the permanent portion of the follicle during cycling (Cotsarelis et al., 1990). The boundary in which label-retaining cells were found to be localized approximates the sebaceous gland as the upper border and the arrector pili muscle insertion point as the lower border. Cytokeratin 15 (K15) immunostaining is a useful marker to highlight the bulge region (Lyle et al., 1999). In addition, CD200 positivity is a useful prospective eSC marker in this region of the human hair follicle (Ohyama et al., 2006).

Bulge cells were the first adult stem cells of the hair follicle been identified and were later shown to be capable of forming hair follicle, interfollicular epidermis and sebaceous glands (Oshima et al., 2001; Cotsarelis, 2006). In addition - at least in murine hair follicles - nestin-positive cells that apparently arise from the epithelial bulge, can also give rise to non-epithelial cells like neurons or Schwann cells (Hoffman, 2006) indicating a lineage-independent pluripotent character. The cells of the bulge region display the greatest in vitro growth capacity and clonogenicity compared to cells from other regions of the hair follicle and epidermis. Cell fate experiments using pulse labelling of nucleotides revealed that the bulge cells give rise to lower follicles, including the outer root sheath, matrix and medulla (Ito et al., 2004). Fluorescent marking of bulge cells, employing the promoter activity of the K15 gene, revealed that "bulge-derived" cells were found throughout all epithelial cell types of the new lower hair follicle and hair shaft, and were also present in the epidermis and sebaceous gland (Liu et al., 2003).

Roh et al. (2005) have confirmed that the human hair follicle bulge area contains keratinocyte stem cells, whereas the hair matrix represents a proliferating and differentiating TA cell compartment. Lyle et al. (1998) showed that human telogen and anagen follicles express K15 and high levels of $\beta 1$-integrin in the basal layer of cells surrounding the telogen club hair (secondary hair germ) and in the anagen bulge region, respectively. As the entire lower follicle epithelium, below the isthmus, has degenerated during the catagen phase of the hair cycle, the telogen follicles represent an enriched source of stem cells. The matrix keratinocytes located at the bottom of the anagen hair 
bulb represent the rapidly proliferating TA cells that differentiate into all the epithelial layers of the hair follicle. These cells do not express K15, and express lower levels of $\beta 1$ integrin than the telogen bulge (Lyle et al., 1998). Both populations form colonies.

\subsection{Molecular controls of eSC fate decisions and maintenance in the hair follicle}

The hair follicle never loses its regenerative capacity, unless this stem cell pool is destroyed (e.g. by autoaggressive immune responses). This implies that eSCs must be maintained in their undifferentiated state for the entire duration of the individual's lifetime. Therefore, the transduction of certain intercellular signals, which result in growth and/or differentiation of bulge cells, must be regulated, since the few stem cells in the niche may cause failure to replenish mature skin tissue or loss of hair. On the other hand, an excess of these cells may lead to excess progenitors and susceptibility to cancer. Clues to the mechanism by which the hair follicle bulge maintains a growth inhibitory environment were obtained by transcriptional profiling of human and mouse hair follicle bulge cells (Tiede et al., 2007). Most obvious transcripts, which are over-represented in the human hair follicle bulge, encode the Wnt inhibitors; Wnt inhibitory factor-1 (WIF1) and Dickkopf-3 (DKK3). Transcripts encoding the Wnt inhibitors, DKK3, Disabled-2 (Dab2) and secreted frizzled-related protein-1 (Sfrp1) are over-represented in the mouse hair follicle bulge. Overexpression of lymphocyte enhancer factor-1 (Lef-1) or $\beta$-catenin in transgenic mice leads to ectopic formation of abnormal hair follicles in interfollicular and oral epithelium, while genetic ablation of Lef-1 leads to arrested follicle development and hairlessness (van Genderen et al., 1994; Gat et al., 1998). Similarly, when the $\beta$ catenin gene is ablated in mice, or when Wnt signalling is inhibited by ectopic expression of DKK1, formation of precursors of mature hair does not take place during embryogenesis. This suggests that the Wnt signalling pathway plays an important role in hair follicle morphogenesis and cycling (O'Shaughnessy et al., 2004). Thus the upregulation of transcripts involved in the inhibition of the Wnt pathway is consistent with the anticipated quiescent state of hair follicle bulge stem cells (Fuchs and Horsley, 2008). Recent findings demonstrate that upon transcription factor-3 (Tcf3) activation, committed epidermal cells induce genes associated with an undifferentiated, Wnt-inhibited state and 
Tcf3 promote a transcriptional program shared by embryonic and postnatal stem cells. These findings suggest that in the absence of Wnt signals, Tcf3 may function in skin stem cells to maintain an undifferentiated state and, through Wnt signalling, directs these cells along the hair lineage (Nguyen et al., 2006).

In support of a quiescent stem cell phenotype, tumour growth factor (TGF) $\beta 2$ or pathway members were also found to be over-expressed in mouse and human bulge cells (Ohyama et al., 2006; Tiede et al., 2007). However, TGF $\beta 2$ is a pleiotropic protein with known positive regulatory effects on epithelial cell proliferation. TGF $\beta$ family members include bone morphogenetic proteins (BMP) and activins. Both the production of the hair shaft in anagen and the initiation of a new hair cycle at telogen are the result of reciprocal interactions between the dermal papilla and the overlying epithelial cells. Secreted factors, such as those of the BMP family, play a crucial role in moderating these interactions. The activin/BMP signalling antagonist follistatin was also selectively overrepresented in the bulge outer root sheath. The blockade of activin signalling by follistatin may also promote maintenance of stem cells quiescence.

Numerous further genes have been identified to be associated with eSC in animal systems (Tiede et al., 2007).

\section{Dermal stem cells and anti-ageing}

\subsection{Dermal stem cells}

Similarly to chondrocytes and osteoblasts, fibroblasts are cells of mesodermal origin; they are the main structural cells of the dermis. Table 1 illustrates the key function of the fibroblasts in the dermis - provision of the foremost elements necessary for the extracellular matrix composition. Fibroblasts synthesize and provide glycosaminoglycans, elastin, fibronectin, laminin and, most importantly, the major structural ingredient of the dermis collagen.

Secretion and composition of various humoral factors such as prostaglandins, leukotrienes and cytokines - among others - is also known as ability of the fibroblasts (Artuc et al., 2002; Werner et al., 2007). 
Several recent studies indicate that the dermis constitution is been maintained by the extracellular matrix and those humoral factors synthesized by the fibroblasts. They also point out that further skin cells, such as keratinocytes and mast cells, cooperate with fibroblasts in order to maintain skin homeostasis (Stark et al., 2004; Artuc et al., 2002).

Skin homeostasis is 'attacked' by the intrinsic ageing process, ultraviolet light and other external irritants resulting in a dramatic change in the structure of dermis. The most remarkable change is the reduction in the level of collagen as a marker of the weakening of the functional ability of dermal fibroblasts (Varani et al., 2004), which is connected directly to the appearance of wrinkles and slacks.

Although fibroblasts are extremely important for the homeostasis of the dermis, there is a significant amount of missing information regarding this cell type. The information gap is most clearly seen in the field of exploring the ways of control over the regenerative abilities of the skin. Recent research demonstrated the existence of undifferentiated cells (stem cells) in every dermal tissue participating greatly in the homeostasis maintenance and regeneration of injured skin. Clonal analysis by Chen et al. (2007) has showed that $6.4 \%$ of the single-cell-derived dermal clones were tripotent and that dermal stem cells represent aprox. $0.3 \%$ of human dermal foreskin fibroblasts.

Using EGF, fibroblast growth factor (FGF)-2, and B27-containing cultures Toma et al. (2001) and Biernaskie et al. (2007) had successfully cultivated multipotent cells (skinderived precursors cells) derived from dermis of mice and humans. The existence of such undifferentiated cells, the fibrocytes, which migrate from the bone marrow and blood has been confirmed by further studies (Bucala et al., 1994; Quan et al., 2004). Fibrocytes are mainly understood as progenitors of fibroblasts; they migrate from blood to the area of dermal injury, infiltrate to the dermis and take part in its restoration. The relationship between fibrocytes and stem cells is, however, still poorly understood.

Dermal stem cells are able to synthesize nestin, fibronectin and vimentin as well as other marker proteins and exhibit differentiation-inducing ability to transform into fat, bone, muscle, liver and nerve cells (Bucala et al., 1994; Toma et al., 2001; Quan et al., 2004; Shi and Chen, 2004; Biernaskie et al., 2007; Chen et al., 2007) (Table 2).

Dermal cells are of mesodermal origin. However, stem cells isolated from the dermis proved to be able to differentiate to the endodermal liver cells and ectodermal nerve cells. 
This made it possible to conclude that dermal stem cells have the ability of multipotent differentiation extending their germ lineage.

Controlling dermal stem cells would make it possible to heighten the extracellular matrix, manage the humoral factors composition, maintain the homeostasis of dermis and regenerate it. Additionally, exchange and co-activity among dermal stem cells and other cell types could make a global activation and rejuvenation of the skin, including sufficient correction of wrinkles and slacks possible.

Giving the fact that the activity of stem cells for dermal regeneration is essential, further progress of the research in this area is required in order to understand the regeneration mechanisms of human skin and to possibly use dermal stem cells in medical and cosmetic procedures in the near future.

\subsection{The dermal papilla stem cells}

Hair shaft production and hair follicle cycling depend on stringent interactions with an underlying, specialized mesenchyme, which also undergoes substantial cyclic remodelling events. Cell proliferation and apoptosis in the hair follicle mesenchyme, i.e., the connective tissue sheath and the dermal papilla, are much less prominent, easily missed events, which occur during narrow time windows in the course of hair follicle cycling (Paus and Foitzik, 2004). During each anagen development, connective tissue sheath and dermal papilla are not only massively remodelled, but are also greatly expanded (Tobin et al., 2003). This strongly suggests the presence of resident mesenchymal precursor cell populations. Moreover, the follicular connective tissue sheath serves as a crucial cell pool for the formation of granulation tissue (which is formed by fibroblasts, endothelial cells, mast cells and macrophages) after substantial skin trauma (Jahoda and Reynolds, 2001). Each anagen development is associated with significant angiogenesis, which likely arises from mesenchymal stem cells residing in the connective tissue sheath (Jahoda et al., 2003). Additional evidence for the existence of a mesenchymal stem cell population is provided by the observation that connective tissue sheath can generate mature mast cells from immature, resident precursor populations (Kumamoto et al., 2003) and can give rise to mesenchymal cells along all classical 
differentiation pathways of mesenchymal stem cells, including not only fibroblasts, but also adipocytes, chondrocytes, hematopoietic and neuronal precursors - both in vitro and in vivo (Jahoda et al., 2003).

Molecular analysis of expression markers for mesenchymal stem cells showed that only Lef- 1 , which forms part of the canonical Wnt/ $\beta$-catenin pathway (DasGupta and Fuchs, 1999), was expressed in all clones. Richardson et al. (2005) showed that these cells grown in the presence of FGF-2 on a laminin substrate gave rise to cells displaying a neural morphology. Immunohistochemistry identified an increase in pan-neurological markers. In support to this neural differentiation, Fernandes et al. (2004) characterized a population of cells capable of both neural and mesodermal differentiation. These cells have been identified within the skin dermis and were termed "skin-derived precursors", In the hair follicle, skin-derived precursors are located in the area comprising the dermal papilla and express proteins like versican and nexin (Richardson et al., 2005). Also human dermal papilla and connective tissue sheath cell cultures could be directed toward adipogenesis or osteogenesis (Richardson et al., 2005). Most recently, Hoogduijn et al. (2006) compared the growth and differentiation characteristics of rat hair follicle-derived dermal stem cells with those of bone marrow mesenchymal stem cells. Follicular dermal cells and bone marrow mesenchymal stem cells were isolated. The adherent hair follicle dermal cells showed a fibroblastic morphology in serum-containing culture medium and were CD44+, CD73+, CD90+. CD34+ mesenchymal stem cells isolated from the bone marrow showing a similar morphology and expressing the same cell-surface markers. Following exposure to appropriate induction stimuli, both cell populations had the capacity to differentiate into various mesenchymal lineages, such as osteoblasts, adipocytes, chondrocytes, and myocytes and expressed neuroprogenitor cell markers. In ex vivo analyses, the authors identified the presence of putative dermal stem cells in the connective tissue sheath and dermal papilla of the hair follicle.

\section{Sebaceous gland stem cells}

\subsection{Sebaceous gland development and cell differentiation}


The development of the sebaceous glands is closely related to the differentiation of the other two epidermal lineages, hair follicles and epidermis (Zouboulis, 2004). At the tenth to twelfth weeks of fetal life a stratum intermedium becomes apparent, and at about the same time developing hair germs are quite distinct. In the following weeks the follicles extend downwards into the dermis and the rudiments of the sebaceous glands appear on the posterior surfaces of the hair pegs. By 13 to 15 weeks the glands are clearly distinguishable arising in a cephalo-caudal sequence from hair follicles. The cells in the sebaceous anlagen are identical to those in the basal layer of the epidermis and the follicular canal.

\subsection{Evidence for a unipotent sebaceous stem cell pool}

The constant sebocyte turnover requires a continuous source of cells to maintain the gland, suggesting the involvement of stem cells. Currently available data on the epidermal stem cell compartment are consistent with the existence of a discrete population of sebaceous gland stem cells in addition to those of the interfollicular epidermis, eSC and hair follicle bulge (Watt et al., 2006; Fuchs and Horsley, 2008). Of the different populations of epidermal stem cells, that of the sebaceous gland is least well characterised. There is good evidence for interdependence of the sebaceous gland and hair follicle: in response to injury or other appropriate stimuli, stem cells in each location can generate all differentiated epithelial lineages (Niemann et al., 2003; Ito et al.; 2005) and in situations in which one organ collapses the other is also often lost (Selleri et al., 2006).

Hair follicle bulge stem cells have, indeed, the capacity to differentiate and produce sebaceous glands, however, there is also evidence suggesting that under steady state conditions local environmental cues restrict the lineages selected by stem cell progeny and that a resident pool of progenitor cells exists within the sebaceous gland (Niemann et al, 2003; Lo Celso et al., 2008). Further evidence supports the existence of a unipotent stem cell pool in the sebaceous gland: retroviral lineage tracing experiments in mouse skin reveal that the sebaceous gland can be marked specifically over multiple hair cycles, supporting the notion that a population of long-living cells can maintain the sebaceous 
gland independent of the hair follicle bulge (Ghazizadeh and Taichman, 2001). Pulsechase experiments in mouse skin further suggested the existence of slow-cycling cells in the gland (Braun et al., 2003) and a small cluster of cells at the base of the sebaceous glands was supposed to be marked by expression of the transcriptional repressor Blimp1 (Horsley et al., 2006). Genetic lineage tracing experiments showed that the Blimp1expressing cells are progenitors that give rise to all cells within the sebaceous gland. Research in this field is still ongoing as evidenced by current contradictory findings, whereas, Blimp1 is not selectively expressed in sebaceous gland progenitor cells, but is also expressed by terminally differentiating cells in the interfollicular epidermis, sebaceous gland and hair follicle (Lo Celso et al., 2008). While Blimp1 binds to and negatively regulates the c-Myc promoter (Horsley et al., 2006), there is no correlation between Blimp1 and c-Myc levels in individual human sebaceous cells, suggesting that additional factors regulate levels of c-Myc protein in sebocytes (Lo Celso et al., 2008).

\subsection{Sebaceous gland stem cells: an at least bipotent epidermal stem cell population}

Clonogenic immortalized human sebaceous gland cells (SZ95 sebocytes) were shown to not only generate cells that undergo sebaceous gland differentiation but also cells that express involucrin and cornifin, differentiation markers expressed in the interfollicular and hair follicle inner root sheath (Lo Celso et al., 2008) (Fig. 5). Evidence that sebaceous gland cells not only differentiate into mature sebocytes but also differentiate into involucrin positive cells was also obtained in a second human sebocyte line, SebE6E7. While evidence is still required to establish conclusively that such cells exist in normal skin, the finding that c-Myc activation results in the appearance of clusters of sebocytes in mouse intefollicular epidermis is certainly consistent with their existence (Braun et al., 2003), as is the observation that Hedgehog signalling can trigger sebaceous gland differentiation in interfollicular epidermis (Allen et al., 2003).

On injection into nude mice SZ95 sebocytes underwent interfollicular epidermal differentiation but did not form hair follicles, leading to the conclusion that they are bipotent rather than multipotent. The location of involucrin positive cells at the periphery of SZ95 sebocyte clones (Lo Celso et al., 2008) raises the alternative possibilities that 
differentiating sebocytes and interfollicular keratinocytes differ in their adhesive properties or that there is a community effect whereby differentiating sebocytes promote the same differentiation pathway in their neighbours. Nevertheless, the possibility that in response to additional stimuli SZ95 sebocytes may be able to give rise to cells of the inner root sheath lineage cannot be excluded.

\subsection{Pathways of sebocyte differentiation}

There is evidence from a variety of mouse models and cell culture systems that c-Myc and $\beta$-catenin exert opposing effects on sebocyte differentiation (Fig. 6). In transgenic mice simultaneous activation of c-Myc and $\beta$-catenin revealed mutual antagonism: c-Myc blocked ectopic hair follicle formation and $\beta$-catenin reduced sebocyte differentiation (Lo Celso et al., 2008). Activation of c-Myc favours differentiation along the lineages of the interfollicular epidermis and sebaceous gland, and results in the appearance of groups of differentiated sebocytes within the interfollicular epidermis (reviewed in Watt et al., 2006; Fuchs and Horsley, 2008). B-lymphocyte-induced maturation protein-1 (Blimp1) negatively regulates c-Myc, which would be consistent with a role for c-Myc in promoting sebaceous differentiation (Horsley et al., 2006; Lo Celso et al., 2008). In contrast, activation of $\beta$-catenin induces de novo hair follicle morphogenesis and regression of sebaceous glands. Indeed, over-expression of c-Myc stimulates sebocyte differentiation, whereas over-expression of $\beta$-catenin stimulates involucrin and cornifin expression in SZ95 sebocytes (Lo Celso et al., 2008). The different effects of Myc and $\beta$ catenin on sebaceous gland differentiation are surprising, because c-Myc has been reported to be a $\beta$-catenin target gene and acts downstream of $\beta$-catenin in intestinal epithelium.

Several lines of evidence also suggest that inhibition of Wnt signalling may be required for sebaceous lineage specification. Expression of a dominant-negative mutant form of Lef1 ( $\Delta$ NLef1) suppresses hair follicle differentiation, stimulating sebocyte and interfollicular epidermal differentiation (Niemann et al., 2003). Additionally, dominantnegative mutations in humans and in mice result in sebocyte tumorigenesis (Takeda et al., 2006). The negative role of Wnt signalling appears to be associated with $\beta$-catenin 
expression: $\triangle$ NLef1 expression results in disruption of $\beta$-catenin signalling (Niemann et al., 2003) and overexpression of Smad7, which promotes $\beta$-catenin degradation through a novel mechanism involving Smad-specific E3 ubiquitin protein ligase 2 (Smurf2), also results in sebaceous gland hyperplasia (Han et al., 2006). The Wnt pathway may also be linked to hedgehog signalling in sebocytes, as overexpression of $\Delta$ NLef1 can lead to upregulation of indian hedgehog in SZ95 sebocytes (Niemann et al. 2003), suggesting that the timing and balance between hedgehog and Wnt signalling is crucial for proper sebaceous development. Hedgehog signalling is the best-characterized signalling pathway involved in sebocyte proliferation. Expression of a mutant smoothen receptor that constitutively activates hedgehog signalling resulted in ectopic sebocyte development (Allen et al. 2003). Similarly, treatment of SZ95 sebocytes in vitro with Indian Hedgehog drove sebocyte proliferation but not differentiation (Niemann et al. 2003). In contrast, inhibition of hedgehog signalling by overexpression of a dominantnegative mutant of Gli2, a downstream transcriptional hedgehog effector, could suppress sebocyte development (Allen et al., 2003).

\subsection{Sebaceous gland and ageing}

In mature skin, the sebaceous gland resides above the bulge bound to the follicular canal with the sebaceous duct. The peripheral cell layer of the sebaceous gland is undifferentiated, expresses keratin 14 and is mitotically active. During differentiation, sebocytes derived from this layer mature in a centrifugal direction towards the centre of the gland, synthesize and accumulate specific lipids, which constitute the major content of sebum, increase their volume, undergo apoptosis, lyse and release their entire content (holocrine secretion) into the sebaceous duct and onto the skin's surface. The number of sebaceous glands remains approximately the same throughout life, whereas their size tends to change with age (Zouboulis and Boschnakow, 2001). The turnover of the sebaceous glands in the aged is slowed down compared to young adults. Interestingly, SZ95 sebocytes maintained under hormone environment compatible with aged individuals expressed higher c-Myc levels than cells maintained in "young" hormone 
environment (Makrantonaki et al., 2006), indicating an enhanced single cell sebaceous differentiation with age.

\section{Clinical importance of skin stem cells}

The self-renewal and multi-lineage differentiation of skin stem cells, both from fetal and adult sources, make these cells attractive for studying the ageing process but also for regenerative medicine, tissue repair, gene therapy and cell-based therapy with autologous adult stem cells not only in dermatology. The factors, which induce successive stages of stem cell commitment during skin and appendage development and maintain, e.g., the "stem-ness" of skin stem cells during development have still to be identified.

On the other hand, the identification of multipotency of skin stem cells will revolutionize skin research, including individual drug testing and pharmacogenomics. SZ95 sebocytes, been able to differentiate into both sebocytes and interfollicular epidermis, provide the first in vitro model with which to study epidermal lineage selection and its role in the ageing process.

As a result, human stem cells have recently attracted so much general interest in many fields of biology and clinical medicine including gerontology, well beyond the traditional borders of skin research. 


\section{References}

Adjaye, J., Huntriss, J., Herwig, R., BenKahla, A., Brink, T.C., Wierling, C., Hultschig, C., Groth, D., Yaspo, M.L., Picton, H.M., Gosden, R.G., Lehrach, H., 2005. Primary differentiation in the human blastocyst: comparative molecular portraits of inner cell mass and trophectoderm cells. Stem Cells 23, 1514-1525.

Allen, M., Grachtchouk, M., Sheng, H., Grachtchouk, V., Wang, A., Wei, L., Liu, J., Ramirez, A., Metzger, D., Chambon, P., Jorcano, J., Dlugosz, A.A., 2003. Hedgehog signaling regulates sebaceous gland development. Am. J. Pathol. 163, 2173-2178.

Artuc, M., Steckelings, U.M., Henz, B.M., 2002. Mast cell-fibroblast interactions: human mast cells as source and inducers of fibroblast and epithelial growth factors. J. Invest. Dermatol. 118, 391-395.

Barrandon Y., Green, H., 1987. Three clonal types of keratinocyte with different capacities for multiplication. Proc. Natl. Acad. Sci. U.S.A. 84, 2302-2306.

Biernaskie, J.A., McKenzie, I.A., Toma, J.G., Miller, F.D., 2006. Isolation of skinderived precursors (SKPs) and differentiation and enrichment of their Schwann cell progeny. Nat. Protoc. 1, 2803-2812.

Braun, K.M., Niemann, C., Jensen, U.B., Sundberg, J.P., Silva-Vargas, V., Watt, F.M., 2003. Manipulation of stem cell proliferation and lineage commitment: Visualisation of label-retaining cells in wholemounts of mouse epidermis. Development 130, 52415255.

Bucala, R., Spiegel, L.A., Chesney, J., Hogan, M., Cerami, A., 1994. Circulating fibrocytes define a new leukocyte subpopulation that mediates tissue repair. Mol. Med. 1, 71-81.

Chen, F.G., Zhang, W.J., Bi, D., Liu, W., Wei, X., Chen, F.F., Zhu, L., Cui, L., Cao, Y., 2007. Clonal analysis of nestin(-) vimentin(+) multipotent fibroblasts isolated from human dermis. J. Cell Sci. 120, 2875-2883.

Clayton, E., Doupe, D.P., Klein, A.M., Winton, D.J., Simons, B.D., Jones, P.H., 2007. A single type of progenitor cell maintains normal epidermis. Nature 446, 185-189.

Conboy, I.M., Conboy, M.J., Wagers, A.J., Girma, E.R., Weissman, I.L., Rando, T.A., 2005. Rejuvenation of aged progenitor cells by exposure to a young systemic environment. Nature 433, 760-764. 
Cotsarelis, G., 2006. Epithelial stem cells: a folliculocentric view. J. Invest. Dermatol. 126, 459-468.

Cotsarelis, G., Sun, T.T., Lavker, R.M., 1990. Label-retaining cells reside in the bulge area of pilosebaceous unit: implications for follicular stem cells, hair cycle, and skin carcinogenesis. Cell 61, 1329-1337.

DasGupta, R., Fuchs, E., 1999. Multiple roles for activated LEF/TCF transcription complexes during hair follicle development and differentiation. Development 126 , 4557-4568.

Fernandes, K.J., McKenzie, I.A., Mill, P., Smith, K.M., Akhavan, M., Barnabe-Heider, F., Biernaskie, J., Junek, A., Kobayashi, N.R., Toma, J.G., Kaplan, D.R., Labosky, P.A., Rafuse, V., Hui, C.C., Miller, F.D., 2004. A dermal niche for multipotent adult skin-derived precursor cells. Nat. Cell Biol. 6, 1082-1093.

Flores, I., Canela, A., Vera, E., Tejera, A., Cotsarelis, G., Blasco, M.A., 2008. The longest telomeres: a general signature of adult stem cells compartments. Genes Dev. 22, 654-667.

Flores, I., Cayuela, M.L., Blasco, M.A., 2005. Effects of telomerase and telomere length on epidermal stem cell behavior. Science 309, 1253-1256.

Fuchs, E., 2008. Skin stem cells: rising to the surface. J. Cell Biol. 180, 273-284.

Fuchs, E., Horsley, V., 2008. More than one way to skin... Genes \& Devel. 22, 976-985.

Gardner, R.L., Beddington, R.S. 1988. Multi-lineage 'stem' cells in the mammalian embryo. J. Cell Sci. Suppl. 10, 11-27.

Gat, U., DasGupta, R., Degenstein, L., Fuchs, E., 1998. De novo hair follicle morphogenesis and hair tumors in mice expressing a truncated beta-catenin in skin. Cell 95, 605-614.

Ghazizadeh, S., Taichman, L.B., 2001. Multiple classes of stem cells in cutaneous epithelium: A lineage analysis of adult mouse skin. EMBO J. 20, 1215-1222.

Giangreco, A., Qin, M., Pintar, J.E., Watt, F.M., 2008. Epidermal stem cells are retained in vivo throughout skin aging. Aging Cell 7, 250-259.

Han, G., Li, A.G., Liang, Y.Y., Owens, P., He, W., Lu, S., Yoshimatsu, Y., Wang, D., Ten Dijke, P., Lin, X., Wang, X.J., 2006. Smad7-induced $\beta$-catenin degradation alters epidermal appendage development. Dev. Cell 11, 301-312. 
Hoffman, R.M., 2006. The pluripotency of hair follicle stem cells. Cell Cycle 5, 232-233.

Horsley, V., O’Carroll, D., Tooze, R., Ohinata, Y., Saitou, M., Obukhanych, T., Nussenzweig, M., Tarakhovsky, A., Fuchs, E., 2006. Blimp1 defines a progenitor population that governs cellular input to the sebaceous gland. Cell 126, 597-609.

Hoogduijn, M.J., Gorjup, E., Genever, P.G., 2006. Comparative characterization of hair follicle dermal stem cells and bone marrow mesenchymal stem cells. Stem Cells Dev. $15,49-60$.

Ito, M., Kizawa, K., Hamada, K., Cotsarelis, G., 2004. Hair follicle stem cells in the lower bulge form the secondary germ, a biochemically distinct but functionally equivalent progenitor cell population, at the termination of catagen. Differentiation $72,548-557$.

Ito, M., Liu, Y., Yang, Z., Nguyen, J., Liang, F., Morris, R.J., Cotsarelis, G., 2005. Stem cells of the hair follicle contribute to wound repair but not to homeostasis of the epidermis. Nat. Med. 11, 1351-1354.

Jahoda, C.A.B., Reynolds, A.J., 2001. Hair follicle dermal sheath cells: unsung participants in wound healing. Lancet 358, 1445-1448.

Jahoda, C.A.B., Whitehouse, C.J., Reynolds, A.J., Hole, N., 2003. Hair follicle dermal cells differentiate into adipogenic and osteogenic lineages. Exp. Dermatol. 12, 849_ 859.

Jensen, K.B., Watt, F.M., 2006. Single-cell expression profiling of human epidermal stem and transit-amplifying cells: Lrig1 is a regulator of stem cell quiescence. Proc. Natl. Acad. Sci. U.S.A. 103, 11958-11963.

Jones, P.H., Watt, F.M., 1993. Separation of human epidermal stem cells from transit amplifying cells on the basis of differences in integrin function and expression. Cell 73, $713-724$.

Krishnamurthy, J., Sharpless, N.E., 2007. Stem cells and the rate of living. Cell Stem Cell $1,9-11$.

Kumamoto, T., Shalhevet, D., Matsue, H., Mummert, M.E., Ward, B.R., Jester, J.V., Takashima, A., 2003. Hair follicles serve as local reservoirs of skin mast cell precursors. Blood 102, 1654-1660. 
Legg, J., Lensen, U.B., Broad, S., Leigh, I., Watt, F.M., 2003. Role of melanoma chondroitin sulphate proteoglycan in patterning stem cells in human interfollicular epidermis. Development 130, 6049-6063.

Levy, V., Lindon, C., Zheng, Y., Harfe, B.D., Morgan, B.A., 2007. Epidermal stem cells arise from the hair follicle after wounding. Dev. Cell 9, 855-861.

Li, A., Simmons, P.J., Kaur, P., 1998. Identification and isolation of candidate human keratinocyte stem cells based on cell surface phenotype. Proc. Natl. Acad. Sci. U.S.A. 95, 3902-3907.

Liu, Y., Lyle, S., Yang, Z., Cotsarelis, G., 2003. Keratin 15 promoter targets putative epithelial stem cells in the hair follicle bulge. J. Invest. Dermatol. 121, 963-968.

Lo Celso, C., Berta, M.A., Braun, K.M., Frye, M., Lyle, S., Zouboulis, C.C., Watt, F.M., 2008. Characterisation of bipotential epidermal progenitors derived from human sebaceous gland: contrasting roles of c-Myc and $\beta$-catenin. Stem Cells 26, 12411252.

Lowell, S., Jones, P., Le Roux, I., Dunne, J., Watt, F.M., 2000. Stimulation of human epidermal differentiation by delta-notch signalling at the boundaries of stem-cell clusters. Curr Biol. 10, 491-500.

Lyle, S., Christofidou-Solomidou, M., Liu, Y., Elder, D.E., Albelda, S., Cotsarelis, G., 1998. The C8/144B monoclonal antibody recognizes cytokeratin 15 and defines the location of human hair follicle stem cells. J. Cell Sci. 111, 3179-3188

Lyle, S., Christofidou-Solomidou, M., Liu, Y., Elder, D.E., Albelda, S., Cotsarelis, G., 1999. Human hair follicle bulge cells are biochemically distinct and possess an epithelial stem cell phenotype. J. Invest. Dermatol. Symp. Proc. 4, 296-301.

Makrantonaki, E., Adjaye, J., Herwig, R., Brink, T.C., Groth, D., Hultschig, C., Lehrach, H., Zouboulis, C.C., 2006. Age-specific hormonal decline is accompanied by transcriptional changes in human sebocytes in vitro. Aging Cell 5, 331-344.

McCullough, J.L., Kelly, K.M., 2006. Prevention and treatment of skin aging. Annals of the New York Academy of Sciences 1067, 323-331.

Moore, K.A., Lemischka, I.R., 2006. Stem cells and their niches. Science 311, 18801885. 
Morrison, S.J., Kimble, J., 2006. Asymmetric and symmetric stem-cell divisions in development and cancer. Nature 441, 1068-1074.

Nguyen, H., Rendl, M., Fuchs, E., 2006. Tcf3 governs stem cell features and represses cell fate determination in skin. Cell 127, 171-183.

Niemann, C., Unden, A.B., Lyle, S., Zouboulis, C.C., Toftgård, R., Watt, FM., 2003.

Indian hedgehog and $\beta$-catenin signaling: Role in the sebaceous lineage of normal and neoplastic mammalian epidermis. Proc. Natl. Acad. Sci. U.S.A. 100(suppl 1), 1187311880.

Niemann, C., Watt, F.M., 2002. Designer skin: lineage commitment in postnatal skin. Trends Cell Biol. 12, 185-192.

O’Shaughnessy, R.F., Yeo, W., Gautier, J., Jahoda, C.A.B., Christiano, A.M., 2004. The WNT signalling modulator, wise, is expressed in an interaction-dependent manner during hair-follicle cycling. J. Invest. Dermatol. 123, 613-621.

Ohyama, M., Terunuma, A., Tock, C.L., Radonovich, M.F., Pise-Masison, C.A., Hopping, S.B., Brady, J.N., Udey, M.C., Vogel, J.C., 2006. Characterization and isolation of stem cell-enriched human hair follicle bulge cells. J. Clin. Invest. 116, 249-260.

Oshima, H., Rochat, A., Kedzia, C., Kobayashi, K., Barrandon, Y., 2001. Morphogenesis and renewal of hair follicles from adult multipotent stem cells. Cell 104, 233-245.

Paus, R., Foitzik, K., 2004. In search of the “hair cycle clock”': a guided tour. Differentiation 72, 489-511.

Potten, C.S., 1974. The epidermal proliferative unit: the possible role of the central basal cell. Cell Tissue Kinet. 7, 77-88.

Quan, T,E, Cowper, S., Wu, S.P., Bockenstedt, L.K., Bucala, R., 2004. Circulating fibrocytes: collagen-secreting cells of the peripheral blood. Int. J. Biochem. Cell Biol. 36, 598-606.

Rando, T.A., 2006. Stem cells, ageing and the quest for immortality. Nature 441, 10801086.

Ressler, S., Bartkova, J., Niederegger, H., Bartek, J., Scharffetter-Kochanek, K., JansenDürr, P., Wlaschek, M., 2006. p16 $6^{\mathrm{INK} 4 \mathrm{~A}}$ is a robust in vivo biomarker of cellular aging in human skin. Aging Cell 5, 379-389. 
Richardson, G.D., Arnott, E.C., Whitehouse, C.J., Lawrence, C.M., Reynolds, A.J., Hole, N., Jahoda, C.A.B., 2005. Plasticity of rodent and human hair follicle dermal cells: implications for cell therapy and tissue engineering. J. Invest. Dermatol. Symp. Proc. $10,180-183$.

Roh, C., Tao, Q., Photopoulos, C., Lyle, S., 2005. In vitro differences between keratinocyte stem cells and transitamplifying cells of the human hair follicle. J. Invest. Dermatol. 125, 1099-1105.

Rossi, D.J., Bryder, D., Zahn, J.M., Ahlenius, H., Sonu, R., Wagers, A.J., Weissman, I.L., 2005. Cell intrinsic alterations underlie hematopoietic stem cell aging. Proc. Natl. Acad. Sci. U.S.A. 102, 9194-9199.

Ruzankina, Y., Pinzon-Guzman, C., Asare, A., Ong, T., Pontano, L., Cotsarelis, G., Zediak, V.P., Velez, M., Bhandoola, A., Brown, E.J., 2007. Deletion of the developmentally essential gene ATR in adult mice leads to age-related phenotypes and stem cell loss. Cell Stem Cell. 1, 113-126.

Selleri, S., Seltmann, H., Gariboldi, S., Shirai, Y.F., Balsari, A., Zouboulis, C.C., Rumio, C., 2006. Doxorubicin-induced alopecia is associated with sebaceous gland differentiation. J. Invest. Dermatol. 126, 711-720.

Sharpless, N.E., DePinho, R.A., 2007. How stem cells age and why this makes us grow old. Nat. Rev. Mol. Cell Biol. 8, 703-713.

Shi, C.M., Cheng, T.M., 2004. Differentiation of dermis-derived multipotent cells into insulin-producing pancreatic cells in vitro. World J. Gastroenterol. 10, 2550-2552.

Stark, H.J., Willhauck, M.J., Mirancea, N., Boehnke, K., Nord, I., Breitkreutz, D., Pavesio, A., Boukamp, P., Fusenig, N.E. 2004. Authentic fibroblast matrix in dermal equivalents normalises epidermal histogenesis and dermoepidermal junction in organotypic co-culture Eur. J. Cell Biol. 83: 631-645.

Stern, M.M., Bickenbach, J.R., 2007. Epidermal stem cells are resistant to cellular aging. Aging Cell 6, 439-452.

Takeda, H., Lyle, S., Lazar, A.J.F., Zouboulis, C.C., Smyth, I., Watt, F.M., 2006. Human sebaceous tumours harbour inactivating mutations in LEF1. Nat. Med. 12, 395-397. 
Thomson, J.A., Itskovitz-Eldor, J., Shapiro, S.S., Waknitz, M.A., Swiergiel, J.J., Marshall, V.S., Jones, J.M., 1998. Embryonic stem cell lines derived from human blastocysts. Science 282, 1145-1147.

Tiede, S., Kloepper, J.E., Bodo, E., Tiwari, S., Kruse, C., Paus, R., 2007. Hair follicle stem cells: Walking the maze. Eur. J. Cell Biol. 86, 355-376.

Tobin, D.J., Gunin, A., Magerl, M., Paus, R., 2003. Plasticity and cytokinetic dynamics of the hair follicle mesenchyme during the hair growth cycle: implications for growth control and hair follicle transformations. J. Invest. Dermatol. Symp. Proc. 8, 80-86.

Toma, J.G., Akhavan, M., Fernandes, K.J., Barnabé-Heider, F., Sadikot, A., Kaplan, D.R., Miller, F.D., 2001. Isolation of multipotent adult stem cells from the dermis of mammalian skin. Nat. Cell Biol. 3, 778-784.

van Genderen, C., Okamura, R.M., Farinas, I., Quo, R.G., Parslow, T.G., Bruhn, L., Grosschedl, R., 1994. Development of several organs that require inductive epithelial-mesenchymal interactions is impaired in LEF-1-deficient mice. Genes Dev. 8, 2691-2703.

Varani, J., Schuger, L., Dame, M.K., Leonard, C., Fligiel, S.E., Kang, S., Fisher, G.J., Voorhees, J.J., 2004. Reduced fibroblast interaction with intact collagen as a mechanism for depressed collagen synthesis in photodamaged skin. J. Invest. Dermatol. 122, 1471-1479.

Watt, F.M., Lo Celso, C., Silva-Vargas,V., 2006. Epidermal stem cells: an update. Curr. Opin. Genetics Develop. 16, 518-524.

Werner, S., Krieg, T., Smola, H., 2007. Keratinocyte-fibroblast interactions in wound healing. J. Invest. Dermatol. 127, 998-1008.

Zouboulis, C.C., 2004. Acne and sebaceous gland function. Clin. Dermatol. 22, 360-366.

Zouboulis, C.C., Boschnakow, A., 2001. Chrono- and photoageing of the human sebaceous gland. Clin. Exp. Dermatol. 26, 600-607 


\section{Legends to the figures}

\section{Fig. 1. Symmetric and asymmetric cell division}

Replication of stem cells can occur either symmetrically when a stem cell division give rise to two identical daughter cells (brown) or asymmetrically when a stem cell produces an identical daughter cell (brown) and a more differentiated daughter cell (blue) (adapted from Morrison and Kimble, 2006). Asymmetric division can be achieved by: i) asymmetric localization of cell polarity regulators, or ii) cell fate determinants, which are segregated to the cytoplasm of only one daughter cell or iii) a regulated orientation of the mitotic spindle, which retains only one daughter cell in the stem cell niche and expose this cell to extrinsic signals regulating self-renewal (purple).

\section{Fig. 2. Self-renewal and differentiation of adult stem cells}

Once stimulated to divide asymmetrically, stem cells produce identical daughter cells (brown) and undifferentiated progenitors (blue). The progenitors in turn produce differentiated effector cells (purple) through subsequent rounds of proliferation. Niche cells (green) communicate with the stem cell via extrinsic signals, where the stem cells themselves are exposed to their own inherent intrinsic signals.

\section{Fig. 3. Organisation of human interfollicular epidermis}

Proliferation of stem cells (red) and TA cells (black) takes place within the basal layer. Upon detachment from the basement membrane keratinocytes initiate a programme of squamous differentiation culminating in the shedding of cornified cells. sb: stratum basale, sc: stratum corneum, sg: stratum granulosum, ss: stratum spinosum

Fig. 4. Hair follicle stem cell populations and their supposed location during the hair cycle (from Tiede et al., 2007. Eur. J. Cell Biol. 86, 355-376). Cyclical changes in hair follicle growth are divided into different stages, referred to as anagen, catagen, and telogen. Hair follicle epithelial and melanocyte stem cells localize to the bulge at the site of arrector pili muscle insertion (see blow-up). During anagen, rapidly proliferating progenitor cells in the bulb generate the hair shaft and its surrounding inner root sheath. 
The onset of catagen is marked by completion of proliferation as well as by apoptosis of the epithelial cells below the bulge. The mesenchymally-derived dermal papilla survives catagen and moves to the lowermost portion of the bulge during telogen, which then forms the secondary hair germ at its base as a pool for melanocyte stem cells, which are moved down from the bulge, and maybe for a second epithelial stem cell population (see blow-up). As the new hair shaft grows in, the old hair is shed. Possible stem cells populations and their locations in the human hair follicle are indicated in the anagen VI hair follicle blow-up illustrations.

Fig. 5. Immortalised SZ95 sebocytes express involucrin, cornifin in addition to markers of sebaceous differentiation (from Lo Celso et al., 2008. Stem Cells 26, 12411252). (A, B) SZ95 sebocytes (A) and keratinocytes (Kt, B) were labelled with antibody to K7 (green) and counterstained with DAPI (blue). Scale bar: $50 \mu \mathrm{m}$. (C, D) Western blots of protein lysates of SZ95 sebocytes (sbc: subconfluent; cfl: confluent), primary keratinocytes (Kt), Seb-E6E7 cells (HPVSebo) and vp keratinocytes (HPV-Kt) probed with antibodies to $\mathrm{K} 7$, with actin or tubulin as a loading control (C), or to involucrin (inv) with tubulin (tu) as a loading control (D). (E-G) SZ95 sebocytes with double labelled with antibodies to keratin 7 (green) and cornifin (red) or transduced with GFP under the control of the involucrin promoter $(\mathrm{F}, \mathrm{G}) . \mathrm{G}$ is a phase contrast image of F. Arrowhead in G shows large, GFP positive cell; arrow shows cell that has rounded up. Scale bars: 50 $\mu \mathrm{m}$. (H-M) DED cultures of SZ95 sebocytes stained with $\mathrm{H}$ and $\mathrm{E}(\mathrm{H})$ or labelled with the antibodies shown. Blue fluorescence: DAPI nuclear counterstain. (I) double labelling for keratin 7 (red) and Nile Red (green). (J) double labelling for Nile Red (green) and involucrin (red). (M) is a merged image of (K, L). Scale bars: $100 \mu \mathrm{m}$. (N, O) Clonal growth of SZ95 cells (N, O) and keratinocytes (Ker, N) on a J2-3T3 feeder layer. Cells were seeded at the plating densities shown and stained for involucrin $(\mathrm{N}, \mathrm{O})$ or CD8 as a negative control (N). Scale bar: $50 \mu \mathrm{m}$.

Fig. 6. The molecular mechanisms that control epithelial stem cell proliferation and differentiation in the skin (from Fuchs \& Horsley, 2008. Genes \& Devel. 22, 976-985). Epidermal stem cells produce three differentiated cell types: the spinous cells, the 
granular cells, and the stratum corneum. The proliferation of epidermal stem cells is regulated positively by $\beta 1$-integrin and TGF $\alpha$, and negatively (-) by TGF $\beta$ signalling. In addition, the transcription factors c-Myc and p63 control epidermal proliferation. Notch signalling and the transcription factors $\mathrm{PPAR} \alpha, \mathrm{AP} 2 \alpha / \gamma$, and $\mathrm{C} / \mathrm{EBP} \alpha / \beta$ control the differentiation of epidermal cells. The hair follicle stem cells in the bulge region produce multiple progenitor cells in the ORS/HG and the matrix, which ultimately produce two differentiated lineages: the hair shaft cells and the inner root sheath cells. The proliferation of the bulge cells is controlled negatively (-) by BMP signalling and the transcription factors NFATc1 and P-TEN, and positively by Wnt signalling. Differentiation of the inner root sheath is controlled by Notch and BMP signalling and the transcription factors CDP and GATA-3. Hair shaft differentiation is controlled by Wnt signalling and its downstream transcription factor Lef1. Matrix cells are controlled by Msx1/2, Ovo1, Foxn1, and Shh. The unipotent sebaceous gland stem cells are regulated negatively by the transcription factor Blimp1 and Wnt signalling, and positively by c-Myc and hedgehog signalling. The differentiation of sebocytes is thought to be directed by PPAR $\gamma$ expression. 
Table 1. Fibroblasts synthesizes extracellular matrix and humoral factors

Extracellular matrix

Collagen

Glycoprotein

Proteoglycan

Matrix modifying proteins
Substance

Type I, III, IV, VI

Laminin, Fibronectin, Thrombospondin

Glycosaminoglycan, Hyaluronic acid, Heparan sulfate, Chondroitin sulfate Matrix metalloproteinases (MMP), Tissue inhibitor of metalloproteinases (TIMP)

Substance

IL-1, 6, 10, TNF $\alpha$

TGF $\beta$, CSF-1, GM-CSF, PDGF, bFGF, IGF-1,2, NGF, KGF, HGF, SCF, VEGF

IL-8, MCP-1, GRO-1, MIP-1,2, RANTES, ENA-78

Phospholipase-A2, PGE2, Prostacyclin, HETE, PAF, NO 
Table 2. Stem cell in dermis tissue

\begin{tabular}{|c|c|c|c|c|}
\hline Stem cells in dermis tissue & Source & Differentiation to & Marker expression & References \\
\hline Multipotent dermal cells & $\begin{array}{l}\text { human } \\
\text { (dermis) }\end{array}$ & $\begin{array}{c}\text { Adipocytes, Osteoblasts, } \\
\text { Chondrocytes, Nerve cells, } \\
\text { Hepatocytes }\end{array}$ & $\begin{array}{c}\mathrm{CD} 13(+), \mathrm{CD} 29(+), \mathrm{CD} 49(+), \\
\mathrm{CD} 105(+), \mathrm{CD} 34(+), \mathrm{Nestin}(-), \\
\text { Vimentin(+), Stro-1(+), CD45(-), } \\
\text { CD106(-), CD133(-) }\end{array}$ & $\begin{array}{l}\text { Chen et al., 2007. J. } \\
\text { Cell Sci. } 120,2875- \\
2883\end{array}$ \\
\hline $\begin{array}{l}\text { Skin derived progenitor cells } \\
\text { (SKPs) }\end{array}$ & $\begin{array}{l}\text { mouse } \\
\text { human } \\
\text { (dermis) }\end{array}$ & $\begin{array}{l}\text { Adipocytes, Smooth-muscle } \\
\text { cells, Nerve cells (glia cells, } \\
\text { schwan cells) }\end{array}$ & $\begin{array}{l}\text { Nestin(+), Fibronectin(+), } \\
\text { Vimentin(+), Slug, Snail, } \\
\text { Twist, Pax3, Sox9 }\end{array}$ & $\begin{array}{c}\text { Toma et al., 2001. } \\
\text { Nat. Cell Biol. 3, 778- } \\
784 \text { - Biernaskie et al., } \\
\text { 2006. Nat. Protoc. 1, } \\
\text { 2803-2812 }\end{array}$ \\
\hline $\begin{array}{c}\text { Dermis derived multipotent stem } \\
\text { cells } \\
(\mathrm{DMC})\end{array}$ & $\begin{array}{c}\text { rat } \\
\text { (dermis) }\end{array}$ & $\begin{array}{l}\text { Adipocytes, Osteoblasts, } \\
\text { Chondrocytes, Nerve cells, } \\
\text { Pancreas cells, Hepatocytes }\end{array}$ & $\begin{array}{c}\text { CD59(+), CD90(+), CD44(+), } \\
\text { VCAM-I(+), ICAM-I(+), CK-19(-), } \\
\text { CD31(-), CD45(-), CD34(-), } \alpha- \\
\text { SMA(-), Desimin(-), Collagen- } \\
\text { Type II(-) }\end{array}$ & $\begin{array}{l}\text { Shi et al., 2004. World } \\
\text { J. Gastroenterol. 10, } \\
\text { 2550-2552 }\end{array}$ \\
\hline Fibrocytes & & Fibroblasts & $\begin{array}{c}\text { CD34(+), CD11 b (+), CD45(+), } \\
\text { HLA-DR(+), CD71(+), CD80(+), } \\
\text { CD86(+), Collagen-Type-I, III(+), } \\
\text { Vimentin(+) }\end{array}$ & $\begin{array}{l}\text { Bucala et al., 1994. } \\
\text { Mol. Med. 1, 71-81- } \\
\text { Quan et al., 2004. Int. } \\
\text { J. Biochem. Cell Biol. } \\
\text { 36, 598-606 }\end{array}$ \\
\hline
\end{tabular}




\section{Figure 1}

\section{Symmetric division Asymmetric division}
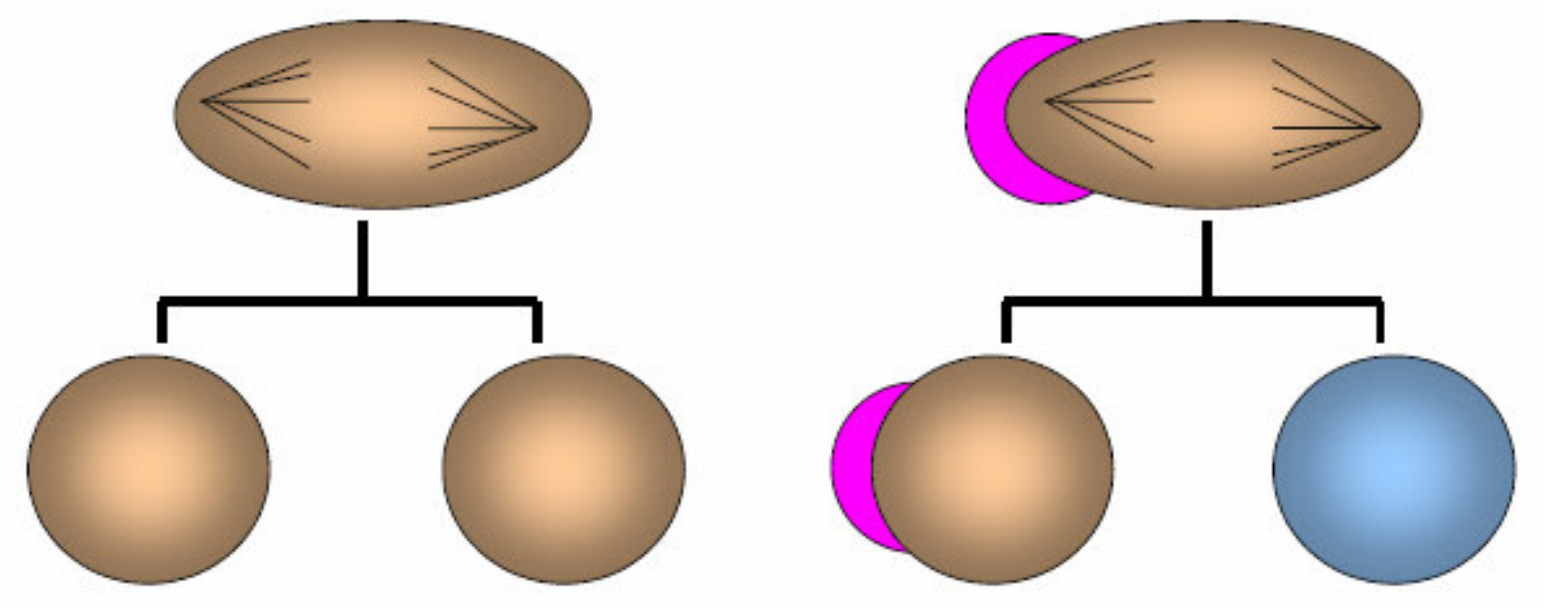
Figure 2

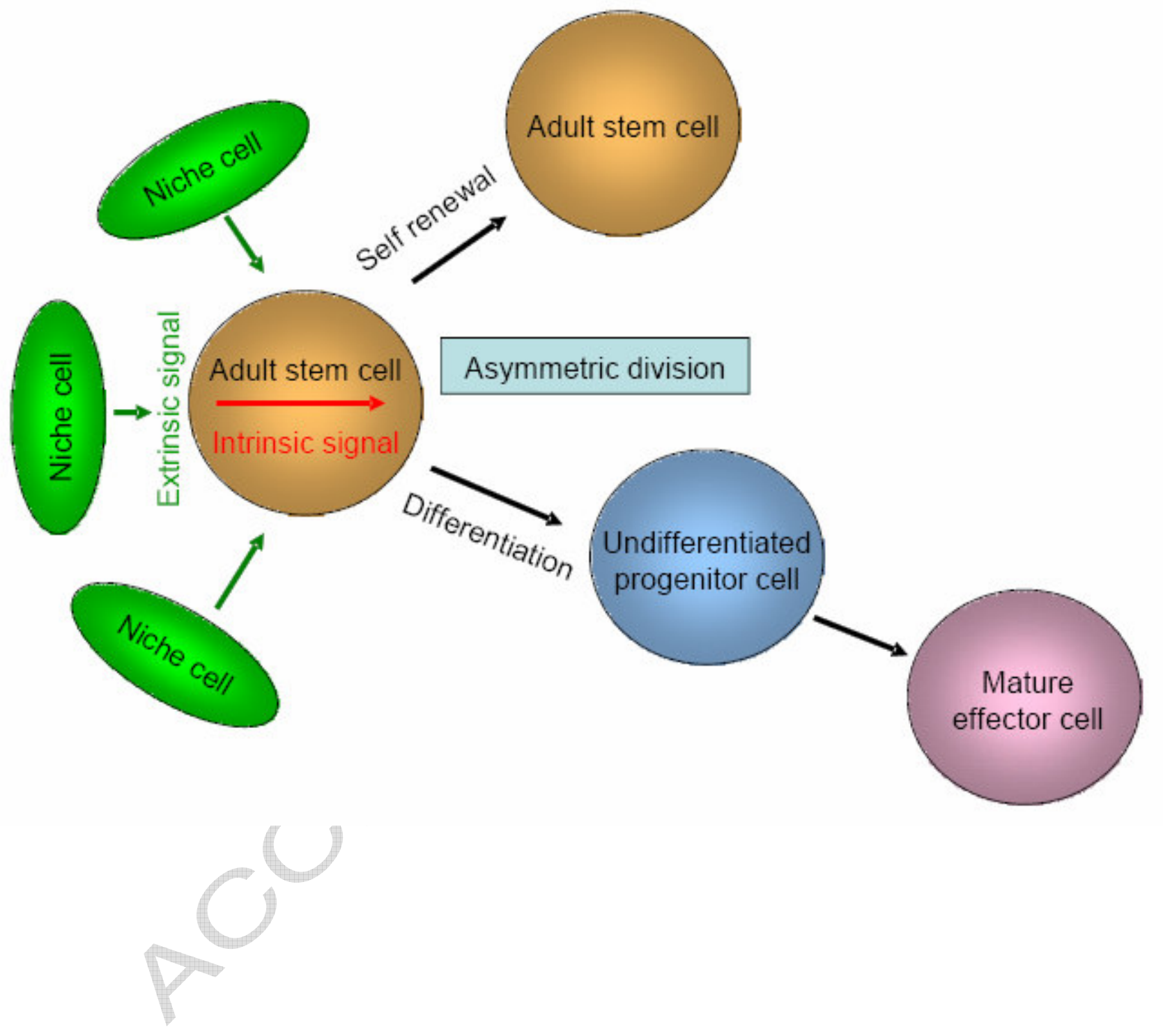


Figure 3

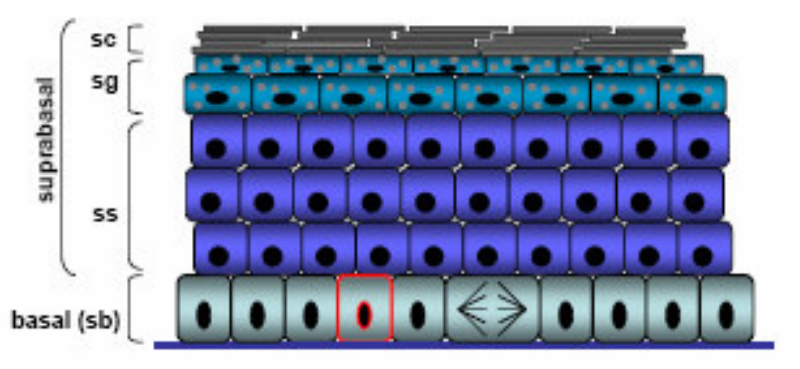


Figure 4

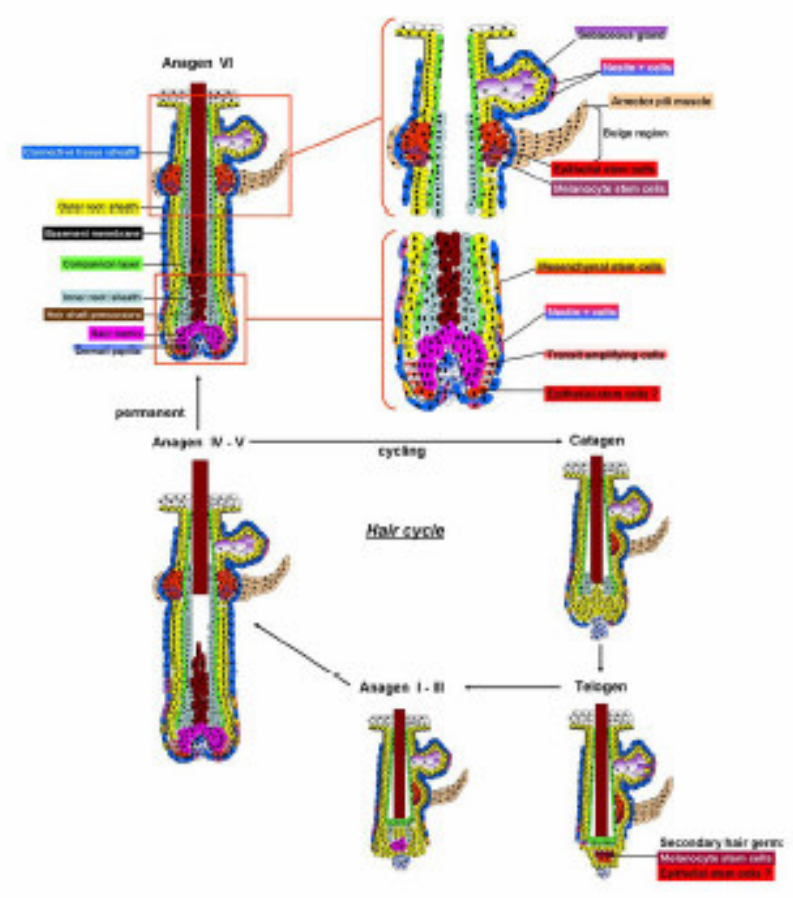



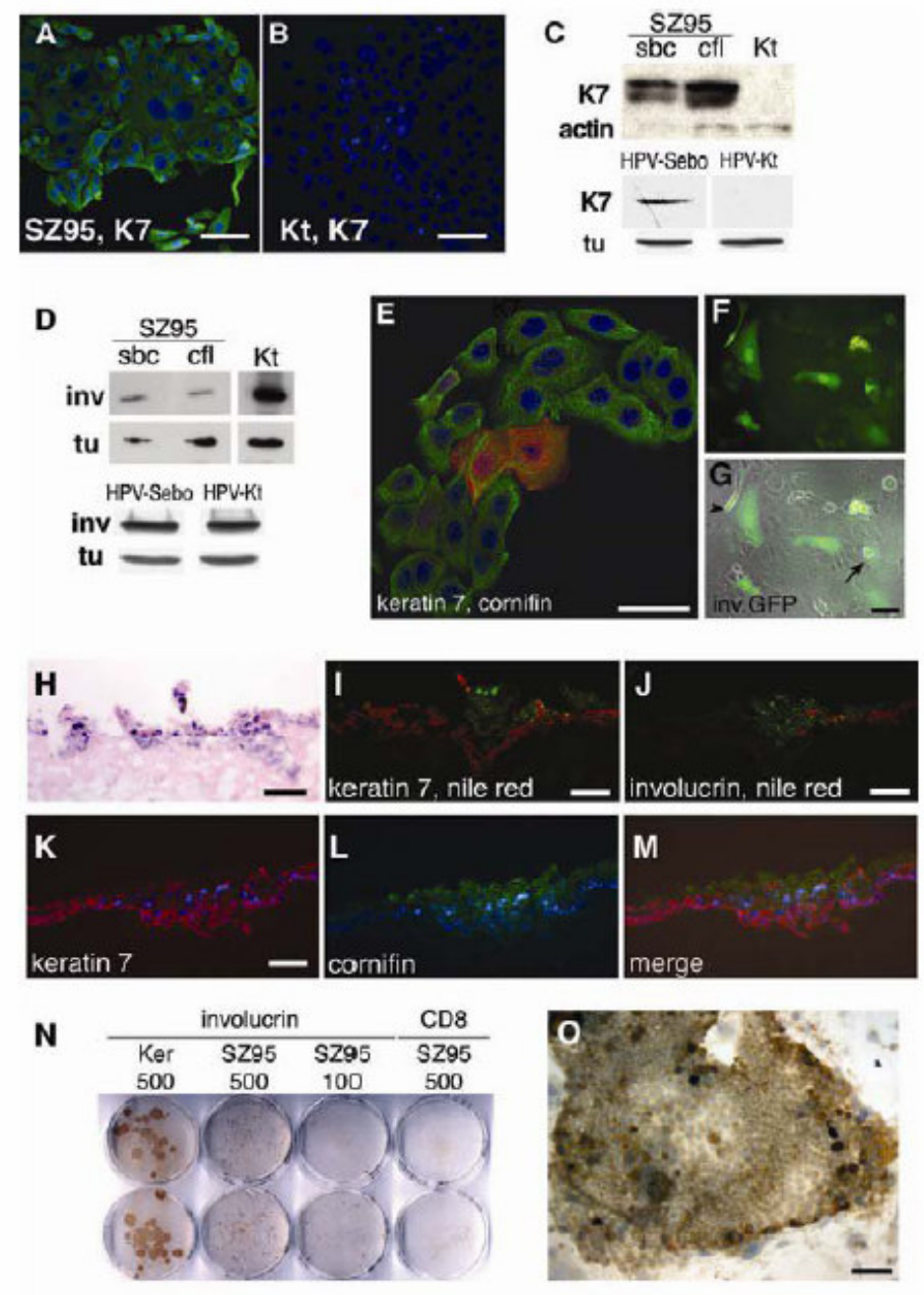

Figure 5 


\section{ACCEPTED MANUSCRIPT}

\begin{tabular}{|l|l|l|l|}
\hline & \multicolumn{1}{c|}{$\begin{array}{c}\text { Proliferative } \\
\text { Progeny }\end{array}$} & \multicolumn{1}{c|}{$\begin{array}{c}\text { Mifferentiated } \\
\text { Cells }\end{array}$} \\
Stem Cell Regulation
\end{tabular}

Figure 6 